Original article

\title{
CYTOLOGY OF GERM CELLS IN THE SCROTAL TESTES OF NATURALLY UNILATERAL CRYPTORCHID WEST AFRICAN DWARF GOATS
}

\author{
G. $\mathrm{OKPE}^{1} \& \mathrm{~T}$. NNAJI ${ }^{2}$ \\ ${ }^{1}$ Department of Veterinary Anatomy; ${ }^{2}$ Department of Veterinary \\ Surgery, University of Nigeria, Nsukka, Nigeria
}

Summary

Okpe, G. \& T. Nnaji, 2018. Cytology of germ cells in the scrotal testes of naturally unilateral cryptorchid West African dwarf goats. Bulg. J. Vet. Med., 21, No. 2, 125-140.

The present study compares the light and ultrastructure of germ cells between testes of normal bucks and the scrotal testes of unilateral cryptorchid bucks using light, electron microscopic and immunohistochemistry techniques. Both testes showed evidence of normal spermatogenesis characterised by presence of complete germ line. In the two groups studied, types A and B spermatogonia were lying close to the basal lamina and exhibited their respective typical morphology. The spermatocytes were of two main types, primary and secondary. The spermatocytes were round and distributed from the basal to the luminal compartments. The primary spermatocytes were in various stages of meiotic divisions. Secondary spermatocytes were observed only at stage 4 of the seminiferous epithelial cycle. Spermatids exhibited complex morphological configuration suggestive of normal spermiogenesis. Evidence of spermiation, characterised by the presence of mature spermatozoa in the lumen of the seminiferous tubule was observed in testes of normal and scrotal testes of unilateral cryptorchid bucks. Eight stages of the seminiferous epithelia cycle were observed in the scrotal testes of the cryptorchid and testes of the normal bucks. Also, cellular composition of each stage was similar in the normal and scrotal testes of the cryptorchid bucks. Similar immunoreactivity expression for vimectin, vascular endothelial growth factor, estrogen and fibroblast growth factor respectively, were recorded in the two groups studied. The findings in the present study suggest the presence of morphologically normal germ cells and normal cell associations in the scrotal testes of naturally unilateral cryptorchid West African Dwarf bucks.

Key words: cryptorchidism, cytology, germ cells, goat, immunohistochemistry, ultrastructure

\section{INTRODUCTION}

Cryptorchidism is a common disorder in man and animals (Barquwi et al., 2004; Tekgul et al., 2009). Germ cell development and its modifications in cryptorchidism have been a subject of many re- searches (Barqawi et al., 2004; Hutson, 2013). Unilateral and bilateral cryptorchidisms have been associated with impaired development of germ cells (Trussel \& Lee, 2004). Deleterious effects 
of cryptorchidism have been demonstrated in all cell stages of spermatogenesis (Goel et al., 2015). Previous studies reported retention of gonocytes and defective transformation of dark spermatogonia to primary spermatocyte, defective onset of meiosis (Hadziselimovic et al., 2007; Cobellis et al., 2014), germ cell degeneration in both retained and scrotal testes (Liu, 2012), congenital spermatogenic arrest (Sengupta, 2012) and reduction in fertility of the contralateral descended testis (Chung, 2011; Goel et al., 2015). However, other authors postulated that the contralateral scrotal testes are normal providing normal number of germ cells, normal distribution of dark and pale spermatogonia and primary spermatocytes (Hadziselimovic, 2008; Okpe \& Ezeasor, 2016). There are therefore contrasting information on the effect of unilateral cryptorchidism on the histology and function of germ cells in the scrotal testis of unilateral cryptorchids.

The present study therefore aims at studying germ cells and cellular associations in the scrotal testes of the unilateral cryptorchid bucks and comparing them with those of normal goats with fully descended testes to elucidate if there were structural and by inference functional abnormalities in the cells as a result of unilateral cryptorchidism.

\section{MATERIALS AND METHODS}

\section{Ethics statement}

The study was approved by the animal welfare Committee of the Faculty of Veterinary Medicine, University of Nigeria, Nsukka.

\section{Experimental animals}

Twenty adult male West African Dwarf (WAD) goats were used for the study.
The bucks were divided into two groups, Group A (10 bucks with fully descended testes) and Group B (10 bucks with unilaterally descended testis). They were kept in two pens at the University of Nigeria, Faculty of Veterinary Medicine demonstration farm. The animals were fed giant star grass, and spent maize grain. Water was provided ad libitum.

With a sharp blade, under local anaesthesia (lidocaine hydrochloride) the testes were dissected out and then cut into very thin slices.

\section{Preparation of samples for light and electron microscopy}

Testes sampled from the bucks in each group were used for light and electron microscopy. The samples were processed for semi and ultrathin sections as described below.

Modified Karnovsky fixative composed of $2 \%$ paraformaldehyde and $2.5 \%$ glutaraldehyde in $0.1 \mathrm{M}$ phosphate buffer at $\mathrm{pH} 7.4$ was used as primary fixative. The fixation was by immersion technique. Very thin testis samples from the bucks in each group were post fixed in $\mathrm{OsO}_{4}$ (osmium tetraoxide) in Millonig's buffer, dehydrated in increasing concentrations of ethanol, cleared in propylene oxide and embedded in epoxy resin. Semi thin sections, $1 \mathrm{~mm}$ thick were cut using an ultra microtome, the sections were stained with toluidine blue and examined using a Leica microscope. Photomicrographs were captured using a moticam Image plus 5 .0 digital camera (Motic China Group Ltd). Ultrathin sections, 50-90 nm thick were obtained using ultramicrotome. They were stained with Reynold's lead citrate and saturated aqueous uranyl acetate. The sections were examined using a Philips CM 10 Transmission Electron Microscope. Micrographs were produced using an 
Olympus Mega View III digital camera (Olympus Corporation Japan) attached to the Transmission Electron Microscope.

\section{Preparation of samples for immunohistochemistry}

Formalin fixed, paraffin embedded testes tissues from normal bucks and scrotal testes of unilateral cryptorchid bucks were sectioned at 5 microns and used to investigate expression of four different proteins, vimentin, vascular endothelial growth factor (VEGF), fibroblast growth factor 1 (FGF-1), and estrogen $\alpha$. Antigen
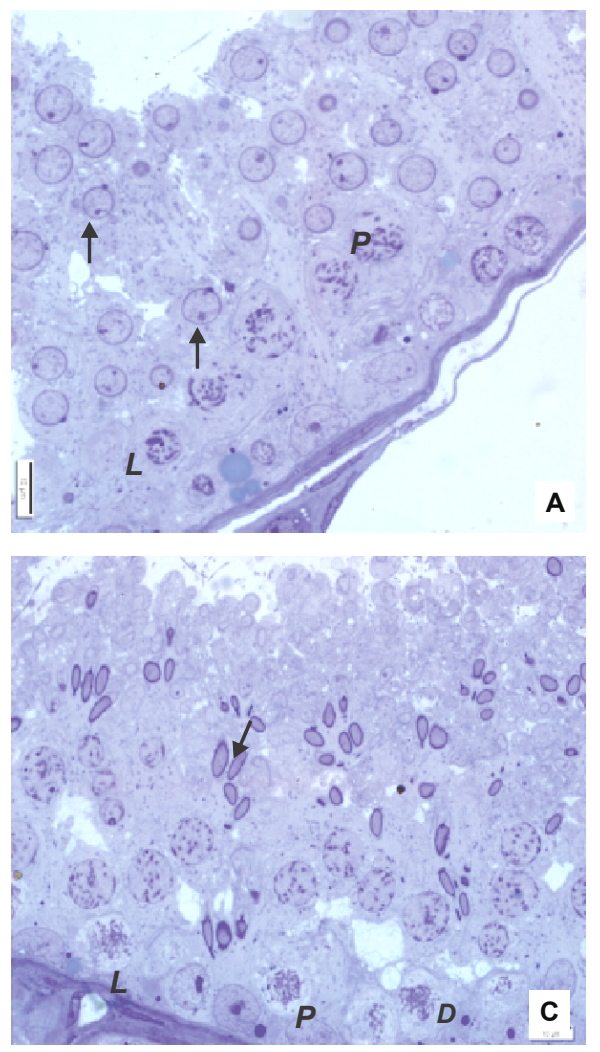

localisation was achieved using monoclonal or polyclonal antibodies combined with avidin-biotin- complex ABC (DAKO Diagnostica Hamburg, Germany) technique as described by Hsu et al. (1981).

\section{RESULTS}

\section{Light microscopy}

The testes parenchyma of normal bucks and scrotal testes of the unilateral cryptorchid bucks are packed by seminiferous tubules. Each seminiferous tubule is sur-
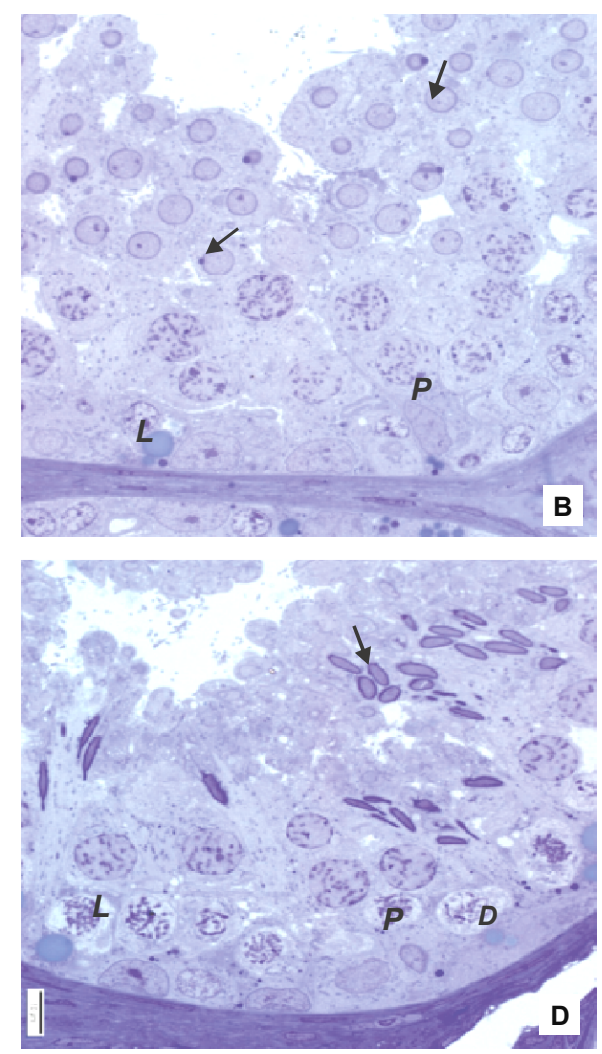

Fig. 1. A, B: Sections of seminiferous tubules of normal bucks (A) and scrotal testis of unilateral cryptorchid bucks (B) showing normal stratified epithelium at stage 1 of the cycle. Note the cap phase spermatids (arrow), leptotene $(L)$ and pachytene (P) spermatocytes. C, D: Sections of seminiferous tubules of normal bucks $(\mathbf{C})$ and scrotal testis of unilateral cryptorchid bucks (D) showing similar germ cell line at stage 2 of the cycle. Acrosome phase spermatids (arrows), leptotene $(L)$, pachytene $(\mathrm{P})$ and deplotene $(D)$ spermatocytes. Toludine blue stain, $\times 200$. 

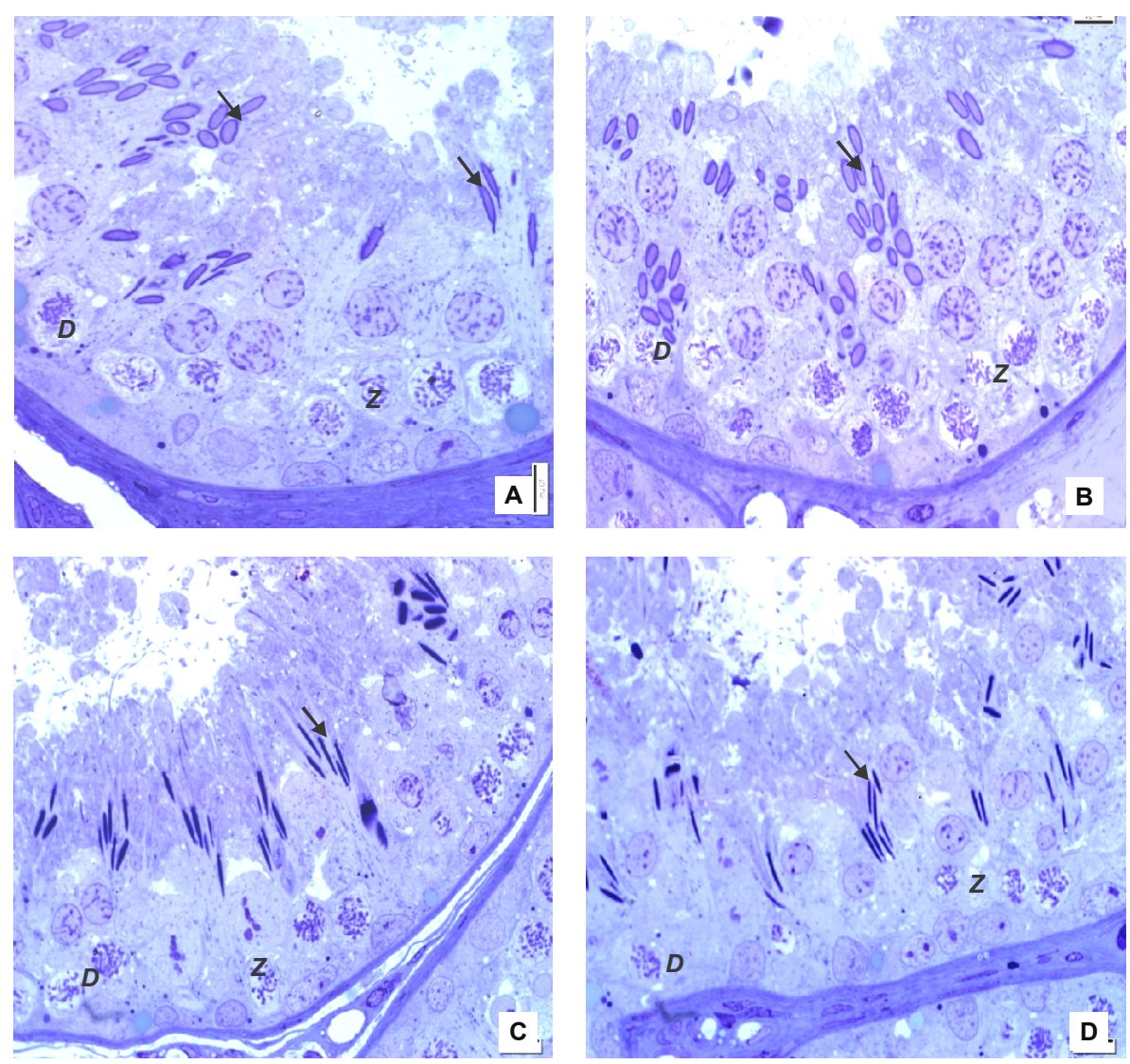

Fig. 2. A, B: Sections of seminiferous tubules of normal buck (A) and scrotal testis of unilateral cryptorchid buck (B) at stage 3. Note the elongated spermatids (arrow), diplotene $(D)$ and zygotene $(Z)$ spermatocytes. C, D: Sections of seminiferous tubules of normal buck $(\mathbf{C})$ and scrotal testis of unilateral cryptorchid buck (D) at stage 4 . Note bundles of filliform shaped spermatids, generations of zygotene (Z) and diplotene (D) spermatocytes. Toludine blue stain, $\times 200$.

rounded by a basement membrane composed of dense collagenous fibres and a narrow stratum of peritubular cells (Fig. 1A, 1B). The seminiferous tubules are lined by stratified germinal epithelium. The stratified spermatogenic cells are composed of spermatogonia, spermatocytes in different stages of meiotic division, round and elongated spermatids and spermatozoa. The spermatogonia appeared as small rounded cells with round or oval nuclei resting on or close to the basement mem- brane (Fig.1A, 1B). The spermatogonia are of two types, A and B. The nuclei of type A spermatogonia contained fine or relatively small granulated chromatin, while the nuclei of the type B spermatogonia contained centrally located nucleus and clumps or relatively large granules of densely stained chromatin, distributed along the nuclear membrane and the nucleoli.

The spermatocytes are located towards the basal part of the epithelium above the 
spermatogonial cells. They appeared larger than the spermatogonia cells. Most of the spermatocytes are in different stages of meiotic division (Fig. 1C, 1D). They are usually arranged in one or more layers within the epithelium. The types of spermatocyte observed are the leptotene primary spermatocytes, zygotene primary spermatocytes, pachytene primary spermatocytes and diplotene primary spermatocytes metaphase spermatocytes and secondary spermatocytes (Fig. 2A). Spermatids occupied several layers at the adluminal compartment. Some of the spermatids are round with pale round nuclei with evenly condensed chromatin, while others appeared elongated. Some of the round spermatids had small round vesicles on their surface membrane, indicating the stage of spermiogenesis. Round spermatids are the most numerous cells found in the seminiferous tubules of the contralateral as well as the normal testes.

The spermatozoa consisted of a lanceshaped head and filamentous tail. The heads of the spermatozoa contain an ellipsoid nucleus with completely condensed chromatin which was deeply stained (Fig. 2B). The heads of the spermatozoa were arranged in parallel arrays embedded in the apical cytoplasm of Sertoli cells, while their tails are directed towards the seminiferous tubule lumen. The seminiferous lumina were patent and some of the lumina contained clumps of spermatozoa depending on the stage of the seminiferous epithelial cycle.

Different types of cellular associations were observed in the stratified seminiferous epithelium in each tubular cross section. Each type of association represented a stage in the seminiferous epithelial cycle of the West African dwarf buck. Eight different types of cell associations were observed in the scrotal testes of the unila- teral cryptorchid bucks and the testes of the normal bucks. The stages were represented by the following cell associations;

Stage 1 was characterised by a generation of apically distributed spermatids (cap phase), two generations of spermatocytes (leptotene and pachytene) and basally located types A and B spermatogonia. The composition and quality of this association was similar in the scrotal testes of the unilateral cryptorchid bucks and the testes of the normal bucks (Fig.1A,1B). Stage 2 comprises acrosome phase spermatid and three generations of primary spermatocytes (leptotene, pachytene and diplotene). The pachytene spermatocytes were numerous (Fig. 1C, 1D). Stage 3 embodies more elongated spermatids with advanced nuclear condensation and two generations of primary spermatocytes (diplotene and zygotene) (Fig. 2A. 2B). Stage 4 consisted of bundles of filiform shaped spermatids within the cytoplasm of Sertoli cells, a generation of secondary spermatocyte and two generation of primary spermatocyte (zygotene and diplotene). Numerous residual bodies were present (Fig. 2C, 2D).

Stage 5 consisted of two generations of spermatids (cap and maturation phases) and two generations of spermatids (preleptotene and pachytene) (Fig. 3A, 3B). The section of the tubule at stage 6 were composed of numerous residual bodies, two generations of spermatids (Golgi and maturation phases) and pachytene spermatocytes characterised by a network like organisation of nuclear chromatin (Fig. 3C, 3D). Stage 7 is characterised by vertical columns of round spermatids and elongated spermatids migrating towards the lumen (Fig. 4A, 4B). However, some elongated spermatids are found at the centre of the epithelium. Pachytene spermatocytes were basally displaced. Stage 8 was characterised by evidence of spermiation in 
the lumen, migration of maturation phase spermatids towards the apex of the epithelium, presence of residual body and inclusions in the adluminal surface. Numerous round spermatids in the cap phase of spermiogenesis were seen arranged in rows. Two generations of spermatocyte (pre-leptotene and the pachytene primary spermatocytes) were among the cells that formed the association (Fig.4C, 4D). The histological features of the contralateral scrotal testis of the cryptorchid bucks were
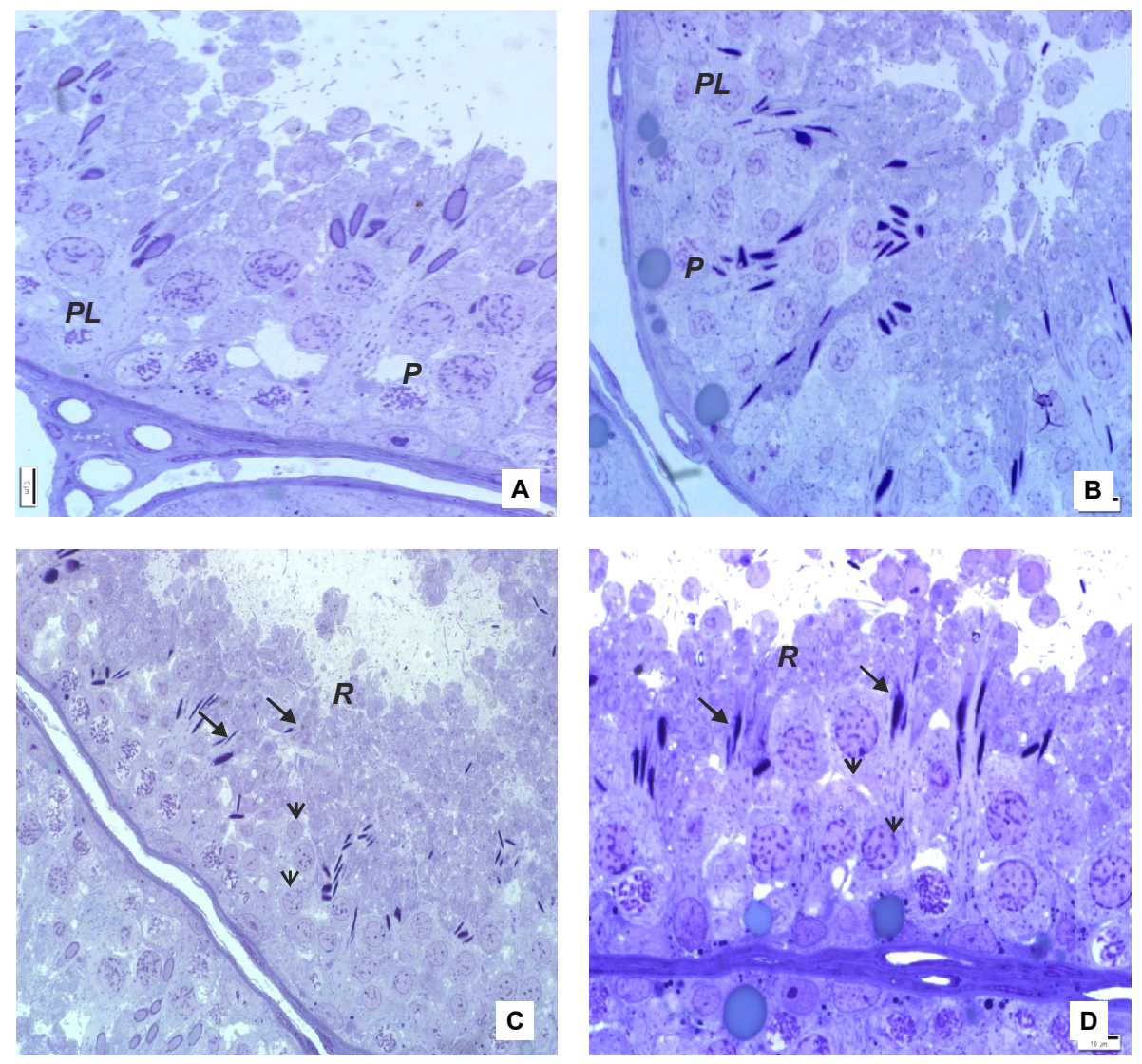

Fig. 3. A, B: Sections of seminiferous tubules of normal buck (A) and scrotal testis of unilateral cryptorchid buck (B) at stage 5. Note a cap phase (arrow), and maturation phase (arrowhead) spermatids, pre-leptotene $(P L)$ and pachytene $(P)$ spermatocytes. C, D: Sections of seminiferous tubules of normal buck $(\mathbf{C})$ and scrotal testis of unilateral cryptorchid buck $(\mathbf{D})$ at stage 6 . Note numerous residual bodies $(R)$, Golgi phase (arrowhead) and maturation phase (arrow) spermatids. Toludine blue stain, $\times 200$. 

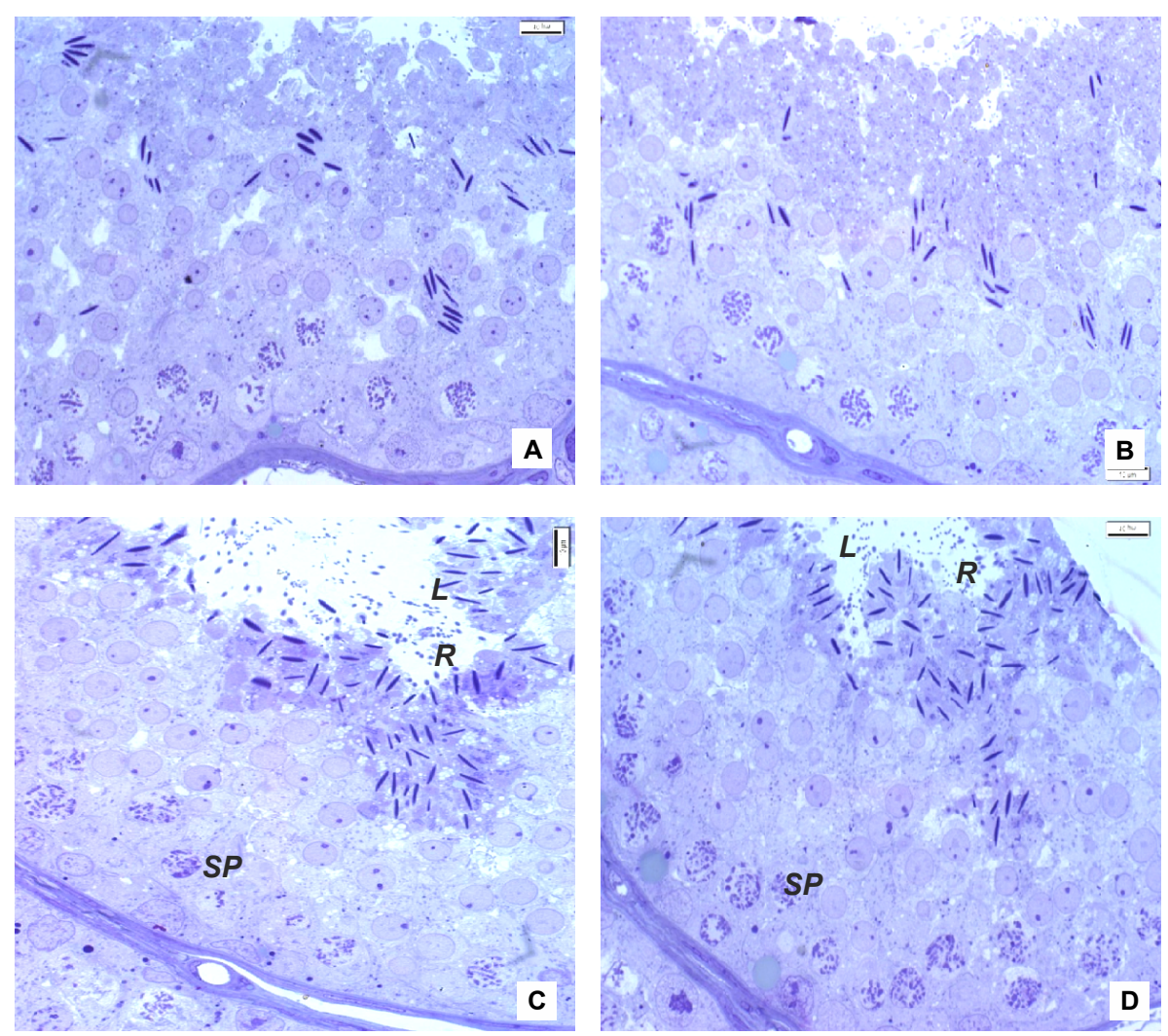

Fig. 4. A, B: Sections of seminiferous tubules of normal buck (A) and scrotal testis of unilateral cryptorchid buck (B) at stage 7 showing elongated spermatids at the centre of the epithelium.

C, D: Sections of seminiferous tubules of normal buck $(\mathbf{C})$ and scrotal testis of unilateral cryptorchid buck (D) at stage 8 . Released spermatozoa at the lumen $(L)$, residual bodies $(R)$ and rows of spermatids $(S P)$. Toludine blue stain $\times 200$.

matozoa (Fig. 5A, 5B). Spermatogonia were usually located on the basal compartment while the spermatocytes and the spermatids were located above the spermatogonia layer in the luminal compartment.

The morphology of the spermatogonia $\mathrm{A}$ and $\mathrm{B}$ and other germ cells was similar in the normal and scrotal testes of the unilateral cryptorchid bucks (Figs. 5C, 5D). The morphology of these spermatogonia cells was typical. Type A-spermatogonium was observed to have an extensive contact area with the basal lamina. The nucleus was very large, round or elongated having the long axis located parallel to the basal lamina. The nucleoplasm was homogeneous and highly euchromatic. The cell contained one reticulated central or eccentric nucleolus. Golgi apparatus was inapparent while few profiles of rough endoplasmic reticulum were found. Type B spermatogonium established less contact area with the basal lamina in comparison with type A (Fig. 5D). The nucleus was round. Densely stained chromatin masses were attached to the nuclear membrane and also to the nucleolus. $\mathrm{Nu}$ - 
merous mitochondria were randomly distributed in the cytoplasm.

Leptotene primary spermatocyte was located close to the basal lamina but in most cases do not make direct contact with the basal lamina (Fig. 5E, 5D). The nuclear chromatin were condensed and surrounded by prominent nuclear membrane. Polysomes and free ribosomes were numerous and randomly distributed in the cytoplasm. The mitochondria were round or ovoid in shape and distributed

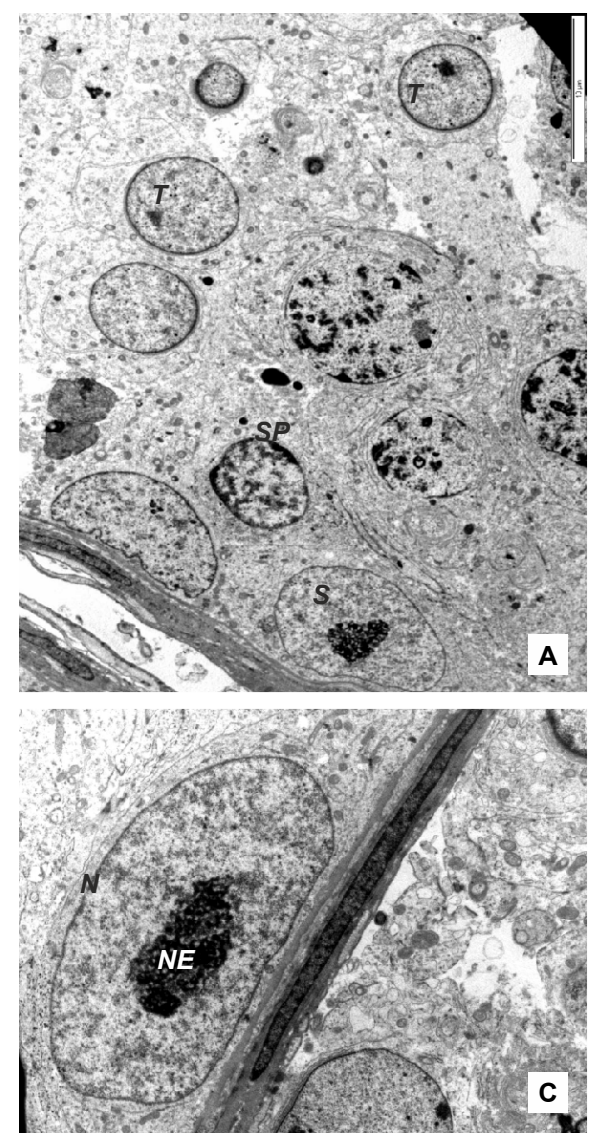

singly or in clusters. Zygotene spermatocytes, compared to the leptotene ones, with larger nucleus and cytoplasm were observed. Condensed chromatins were apparent. Synaptonemal complexes were seen between homologous chromosomes. The mitochondria were arranged in groups, connected by dense intermitochondrial substances. Profiles of rough endoplasmic reticulum were scanty in the cytoplasm.

Pachytene primary spermatocyte was larger than the zygotene spermatocyte and

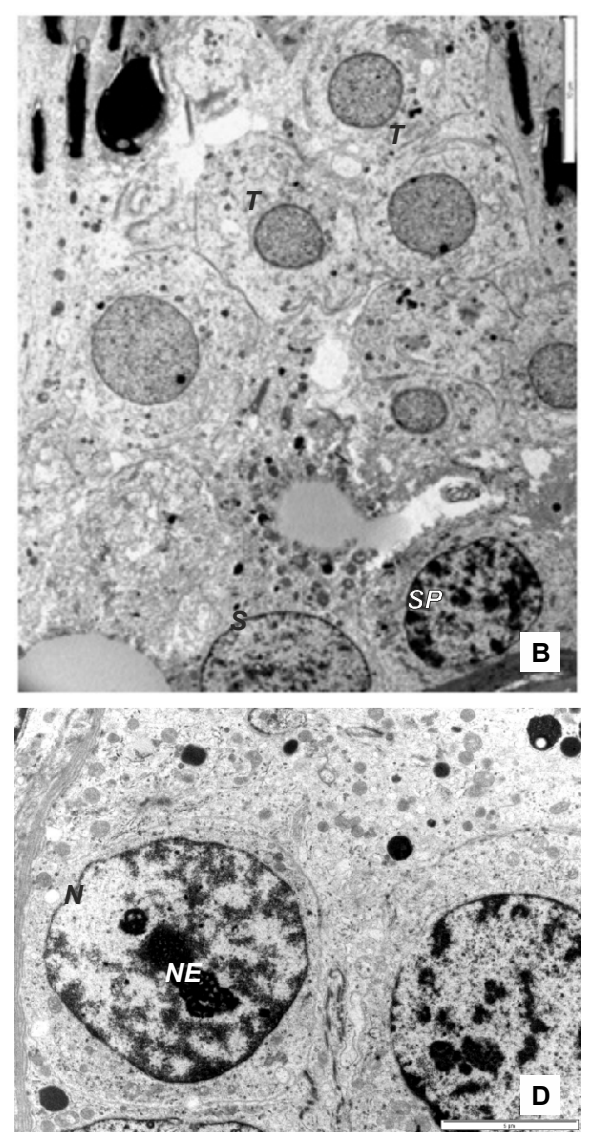

Fig. 5. Electron micrographs of sections of seminiferous tubules from normal buck (A) and scrotal testis of unilateral cryptorchid buck (B) showing normal germ lines. Note spermatogonia $(S)$, spermatocytes $(S P)$, and spermatids $(T)$; $\mathbf{C}$ : Spermatogonium type A, showing euchromatic nucleus $(N)$ and nucleolus $(N E)$; D: Spermatogonium type B from the scrotal testes of a cryptorchid buck - round nucleus $(N)$ and centrally located nucleolus $(N E), \times 19000$. 

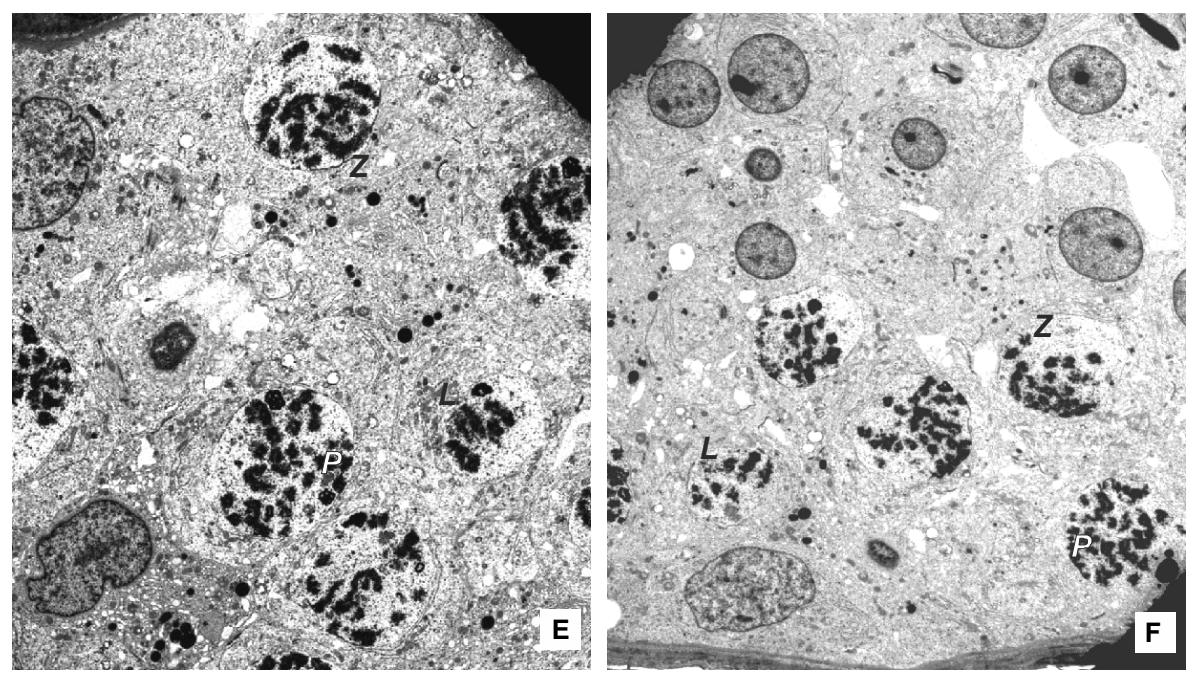

Fig. 5. Electron micrographs of seminiferous tubules from normal $(\mathbf{E})$ and scrotal testis of unilateral cryptorchid buck $(\mathbf{F})$. Different stages of spermatocytes: leptotene $(L)$, pachytene $(P)$ and zygotene $(Z)$ spermatocytes, $\times 19000$.

contained prominent nucleus (Fig. 5E, $5 \mathrm{~F}$ ). The nuclear chromosomes were more condensed in comparison to the previous stages. The synaptonemal complexes were very prominent. In some pachytene spermatocyte profiles, small clumps of heterochromatin were found under the inner nuclear membrane. The nucleolus was reticulated and eccentrically located. In the cytoplasm, the mitochondria were arranged in clusters, held together by intermitochondrial complexes. The agranular and the granular endoplasmic reticula were distributed peripherally.

Diplotene primary spermatocyte was characterised by deeply stained chromatin clumps. The diplotene spermatocyte was larger than the pachytene spermatocytes. The chromosomes lack synaptonemal complexes. Most of the mitochondria were no more in clusters.

Secondary spermatocyte was round, smaller than the diplotene spermatocyte but bigger than the round spermatids (Fig. $5 \mathrm{G})$. Chromatin was uniformly distributed in the nucleus; however, clumps of dense heterochromatin were seen under the nuclear envelope. The mitochondria were randomly distributed in the cytoplasm.

Golgi phase spermatid was round, with round nucleus containing homogenously distributed chromatin (Fig. 5H). Accumulated acrosome vesicles from Golgi apparatus were seen on one pole of the nucleus. These vesicles later coalesced, adhered to the nucleus forming an electron dense granule, the acrosome. Cap phase spermatid was round with a round nucleus containing uniformly distributed chromatins. The acrosome was flattened on the surface of the nucleus, giving rise to membrane like structure, the head cap. In acrosome phase spermatids, the head cap covered half of the nuclear surface. The acrosome granules were more electron dense compared to the preceding phase. Centrioles were found close to the nucleus at the pole opposite the acrosomal granules. At later stages the nucleus was elongated and flattened, the chromatins were 


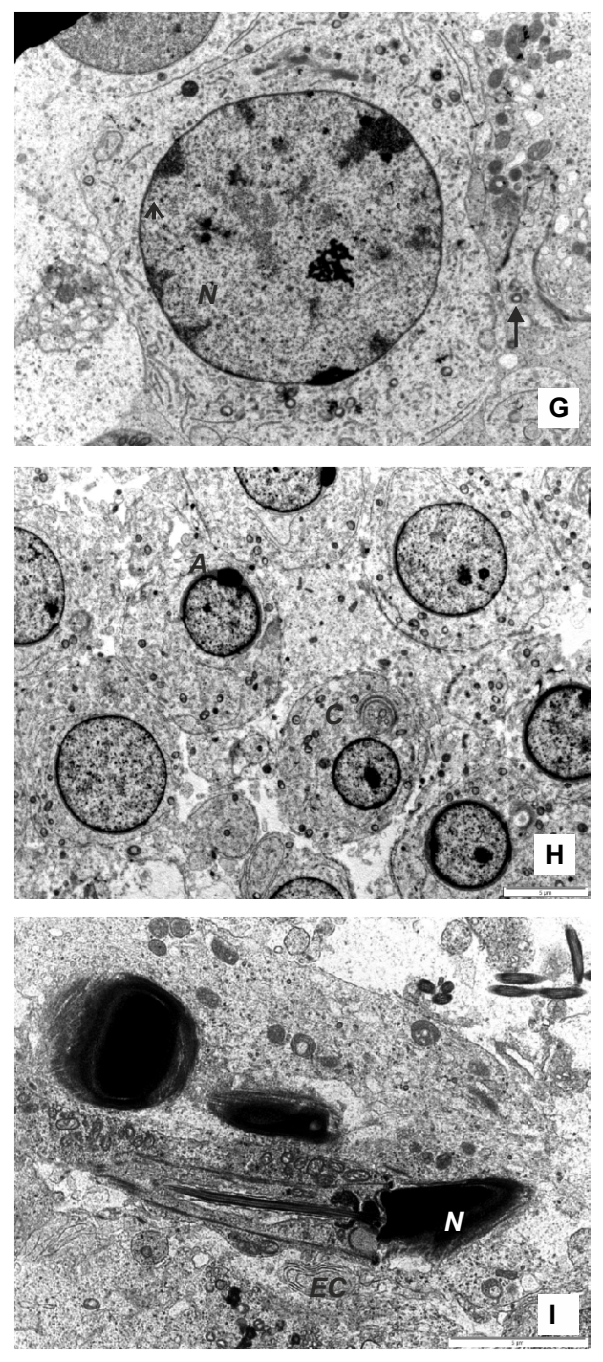

Fig. 5. Electron micrograph of secondary spermatocyte from the scrotal testis of a cryptorchid buck. G: Euchromatic nucleus $(N)$ and randomly distributed mitochondria (arrow); H: Spermatids at different stages of spermiogenesis - note the cap phase $(C)$, and the acrosome phase $(A)$; I: Maturation phase spermatid: flattened nucleus $(N)$ and ectoplasmic specialisations $(E C) ; \times 19000$.

more condensed. The acrosome became more projected and the content was more electron-dense. A zone of low electron density was observed between the chromatin and the nuclear envelope. This zone appeared to be composed of redundant nuclear envelope. Microtubules were arranged as broom sticks and appeared to have originated close to the nuclear rings. Maturation phase spermatid, the redundant nuclear envelopes form small pocket like spaces and the microtubules become inconspicuous. At maturation phase proper (Fig. 5I), the projections of the acrosome and the redundant nuclear envelope were not conspicuous. The nucleus was completely flattened, spermatids that were in contact with Sertoli cell, had their surfaces covered by cisterns of smooth endoplasmic reticulum (ectoplasmic specialization). Later in this phase, the different components of the spermatozoon differentiated into the head and tail, neck, middle piece, principal piece and end piece.

\section{Immunohistochemistry}

Vimectin filaments were immunolocalised to the cytoplasm of Sertoli cells, Leydig cells and peritubular myoid cells in the normal testes and scrotal testes of the unilateral cryptorchid bucks. Sertoli cells showed vimentin positive extensions projecting towards the developing spermatid bundles. The intensity and pattern of vimentin filament staining was more marked in the scrotal testes of the unilateral cryptorchid than those of the normal bucks (Fig. 6A, 6B).

Limited expression of VEGF was observed in the cells of the normal testes and those of the contralateral scrotal testes of the hemicryptorchid bucks (Fig. 6C, 6D). Similar VEGF immunostaining expression was markedly expressed in the interstitium in both groups of bucks usually associated with Leydig cells and vascular endothelial cells. Immunoreactivity expression was 
weakly present in the cytoplasm of Sertoli cells and spermatogenic cells.

Immuno-labelling for estrogen $\alpha$ receptors was markedly expressed in Leydig cells and vascular endothelial cells, vaguely expressed in the germ cells. The intensity of the expressions was higher in the scrotal testes of the cryptorchids compared to the testes of the normal bucks (Fig. 6E, 6F).

Moderate FGF-1 immunostaining was observed in the cytoplasm of germ cells. Marked immunostaining of FGF was observed in the cytoplasm of Leydig cells, and the entire interstitium, more pronounced in the endothelium of blood vessels. The staining intensity of FGF was similar in the testes of normal bucks and
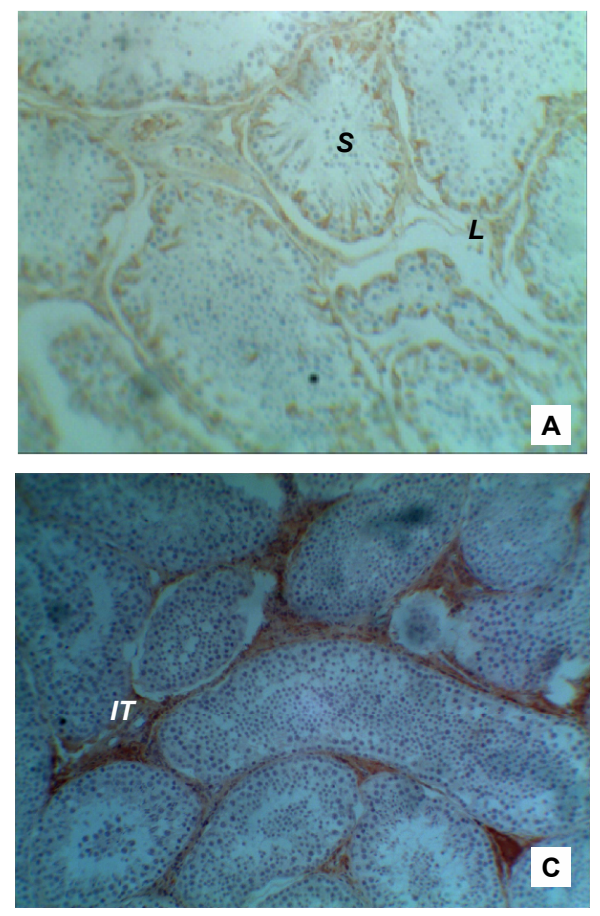

the contralateral scrotal testes of the unilateral cryptorchid bucks (Fig. 6G, 6H).

\section{DISCUSSION}

Histological examinations showed that the cross sections of seminiferous tubules of the contralateral scrotal testes were not different from those of the testes of the normal bucks. They all manifested evidence of active spermatogenic activity.

The testicular tissue is composed of convoluted seminiferous tubules, interstitial compartment, and excurrent duct system. Caprine seminiferous tubules are shown to occupy most of the testicular parenchyma. The seminiferous tubules are surrounded by a distinct boundary tissue
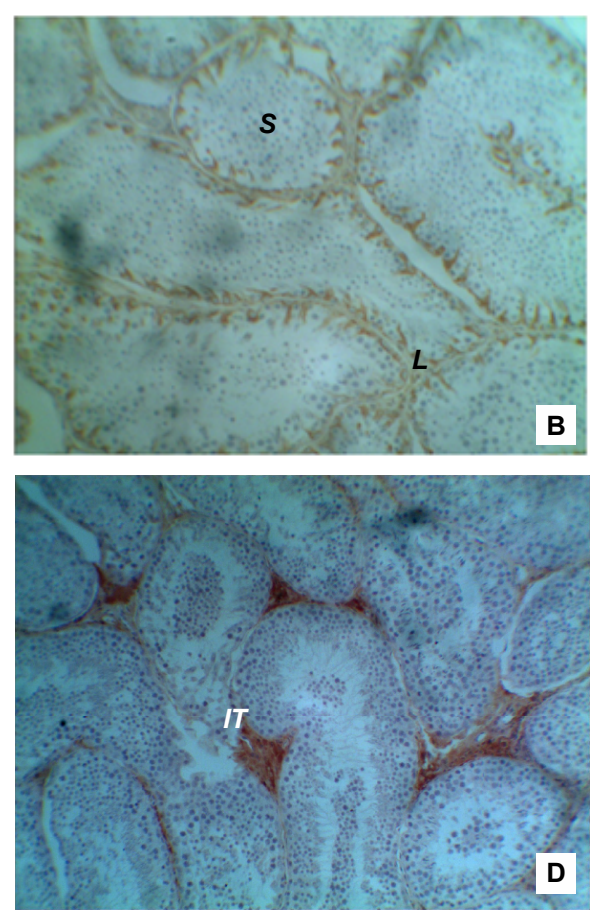

Fig. 6. A, B. Cross section of seminiferous tubules from normal testes (A) and scrotal testes of a cryptorchid buck (B). vimentin expression in Sertoli cell $(S)$, Leydig cell $(L)$. Immunohistochemistry vimentin $\times 400$; C, D. Cross section of the seminiferous tubules from normal testes $(G)$ and scrotal testes of a cryptorchid $(\mathrm{H})$. Marked VEGF expression in Leydig cells and the entire interstitium (IT). Immunohistochemistry VEGF $\times 400$.

BJVM, 21, No 2 

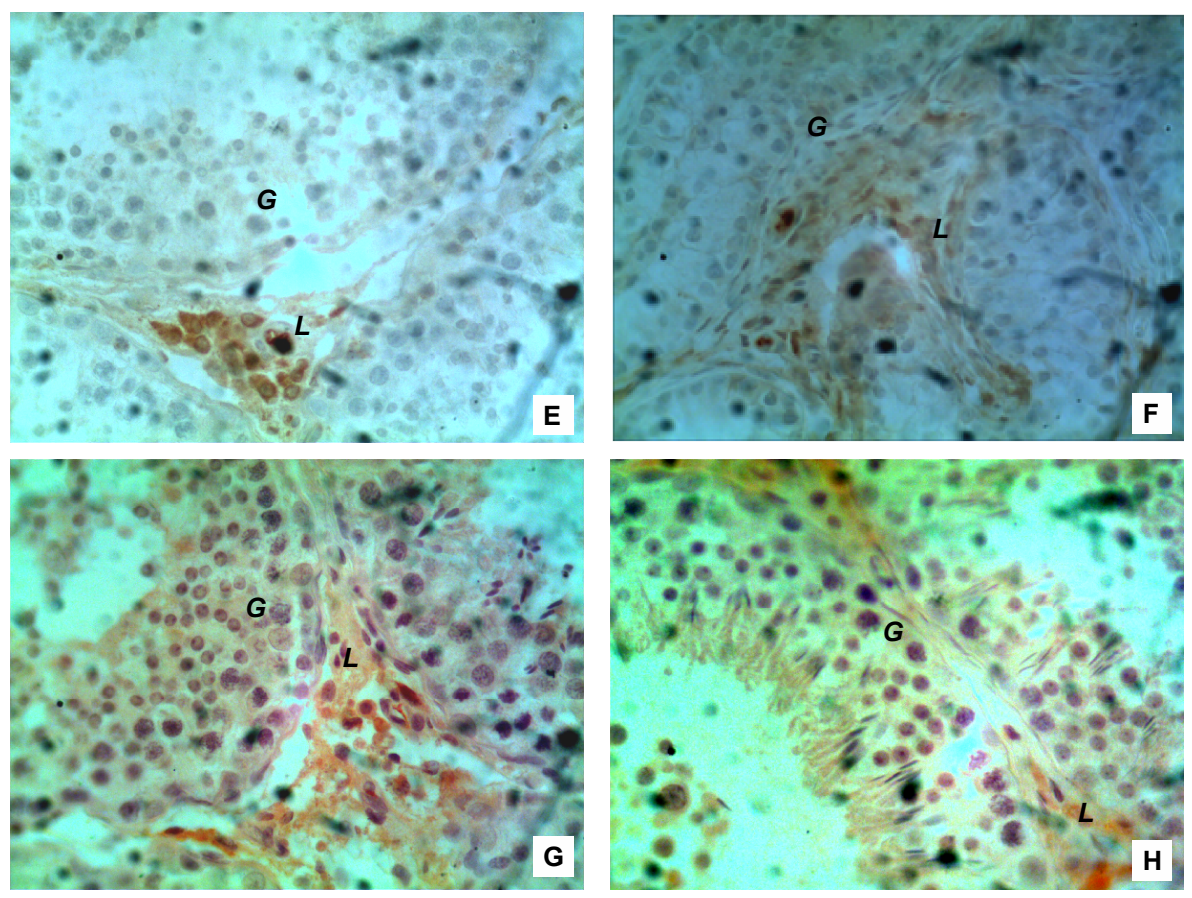

Fig. 6. E, F: Cross section of seminiferous tubules from normal testes (E) and scrotal testes of a cryptorchid buck (F). Estrogen expression in Leydig cells $(L)$ and mild expressions in the germ cells

$(G)$. Immunohistochemistry estrogen $\times 400 ; \mathbf{G}, \mathbf{H}$ : Cross section of the seminiferous tubules from normal testes $(\mathrm{G})$ and scrotal testes of a cryptorchid $(\mathrm{H})$. Marked expression of FGF in the cytoplasm of Leydig cells $(L)$ and moderate expressions in the germ cells $(G)$. Immunohistochemistry FGF $\times 400$.

and lined by stratified epithelium composed of non-dividing Sertoli cells and highly proliferating spermatogenic cells. These findings agree with the previous studies in other breeds of goat (Sarma \& Devi, 2012). Caprine germ cells in the seminiferous tubules of the contralateral scrotal testes and the descended testes of the normal bucks are present in four morphologically different groups: spermatogonia, spermatocytes, spermatids, and spermatozoa.

Spermatogonia are located in the basal compartment while the spermatocytes and young spermatids are found in the mid and luminal portions of the tubule respectively. In the present investigation, only the type $\mathrm{A}$ and $\mathrm{B}$ spermatogonia were identified. The identification was based on size of the cell, nuclear shape, and contact area with the basal lamina. The histological features of these spermatogonia are in consonance with the description in other breeds of goat as well as other ruminants (Mohammed et al., 2011). This finding suggests that retention of one testis in the abdominal cavity does not affect the histology of the germ cells in the contralateral descended testes in unilateral cryptorchidism. The normal histology of the spermatogonia is an indication that adult sperm cell pool is properly established. This further suggests adequate maturation of hypothalamic-pituitary-testicular axis. The spermatogonium histology as reported in the present study is different 
from the observations of Akre et al. (2009) and Goel et al. (2015) who reported lack of transformation of gonocytes to A spermatogonium in the contralateral scrotal testes of unilateral cryptorchids. Spermatocytes in various stages of meiotic divisions were observed in the scrotal testes of the unilateral cryptorchids as well as the testes of normal bucks. This finding most probably indicate normal germ cell population in the scrotal testes of unilateral cryptorchid bucks. This finding further corroborates our earlier report of existence of similarity in germ cell population between the scrotal testes of unilateral cryptorchid bucks and those of the normal bucks (Okpe \& Ezeasor, 2016). However, Huff et al. (2001) reported failed onset of meiosis and appearance of primary spermatocytes in the contralateral descended testes of unilateral cryptorchid patients. Though the disparity in the findings could be due to dimorphism in human cryptorchidism, we suggest further investigation. Round spermatids are located in the adluminal part of the seminiferous epithelium and undergo a complex series of cellular transformation (spermiogenesis). The round spermatids are mononucleated, a demonstration of normal meiotic cytokinesis in the seminiferous tubules of the scrotal testes of unilateral cryptorchid bucks. Binucleated spermatids was reported as representing failed meiotic cytokinesis (O’Donnell et al., 2011). The acrosomes were properly developed in spermatids of the normal testes and the contralateral scrotal testes of the unilateral cryptorchid bucks, suggesting proper spermatid Golgi apparatus vesicle mediated trafficking or microtubular dynamics.

Spermiogenesis takes place via four defined phases: Golgi, cap, acrosomal, and maturation phases. The main mor- phologic changes during spermiogenesis are formation of the acrosome, condensation of the nuclear chromatin, outgrowth of a tail, and loss of excess cytoplasm. These findings are supported by reports of previous studies on caprine testes (Junior et al., 2012). Similar observations were reported in bovine testis (Wrobel, 1998). Spermiation, characterised by mature elongated spermatids lined along luminal edge and the tubular lumen were observed in both groups of goats. This finding is an evidence of normal spermiation suggestive of effective dissolution of an integrinbased focal adhesion like junction between Sertoli cells and spermatids as described by Beardsley et al. (2006).

In the present study, eight stages of the seminiferous cycle were observed. The staging was based on morphological changes of germ cell nuclei as described by Ortavant (1958). This finding is similar to what has been reported in other breeds of goats (Onyango et al., 2000) boars (Bearden et al., 2004), rams (Guraya, 2000) and donkeys (Chiarini-Garcia, 2009). The present light and ultrastructural descriptions of the contralateral scrotal testes and the descended testes of the normal bucks is in consonance with the reports of previous investigations on the testicular morphology of the goat (Singh \& Ezeasor, 1989; Onyango et al., 2000).

The expressions of the cytoskeletal filaments vimentin have been established as markers for cell differentiation (Lydka et al., 2011). The normal testes and the scrotal testis of the cryptorchid bucks showed positive immunolabelling for vimentin. Sertoli cell vimentin positivity is a demonstration that the Sertoli cells are matured (Veronesi et al., 2009). By inference, the Sertoli cells of the normal testes and those of the scrotal testis of the cryptorchid bucks as observed in the present 
study are matured. The expression of vimentin and the immunohistochemical labelling of the vessels corresponds with the findings described in the normal mature testes in horses (Maekawa et al., 1996). However, this appears to be the first investigation in caprine cryptorchidism.

VEGF immunoreactivities were abundantly distributed in the gonads of normal testis and scrotal testes of unilateral unilateral cryptorchids, mainly associated with Sertoli cells, Leydig cells and spermatogenic cells, and weakly present throughout the vascular endothelial cells. Similar expression of VEGF immunoreactivity has been reported in Yak unilateral cryptorchidism (Chen et al., 2015)

Identification of the sites of expression of estrogen is vital, as estrogen has been demonstrated to fascilitate spermatogenesis and other testicular functions (Nanjappa et al., 2016). A slight difference in the staining intensity was observed between Leydig cells from the testes of normal bucks and those of the scrotal testes of the cryptorchid bucks. Those of the cryptorchid bucks expressed stronger staining than those of the normal bucks. These findings demonstrate that estrogen receptors are present in the testes of goats and the stronger staining of Leydig cells in the scrotal testes of unilateral cryptorchid bucks is most probably an indication of improved testosterone metabolism as estrogen receptor has been demonstrated as a major regulator of $17 \mathrm{~B}$ estradiol effects on reproduction (Nanjappa et $a l ., 2016)$. This may provide an explanation for the normal histology of germ cells in the scrotal testes of cryptorchid bucks as reported in the present study. The localisation of estrogen receptors are speciesspecific and have been demonstrated in mice and Vole banks (Bilinska et al., 2003; Makinen et al., 2001).
In the testis, FGFs are involved in testicular angiogenesis, germ cell proliferation, initiation of spermatogenesis, and Leydig cell steroidogenesis (Wagener et al., 2003; Wahlgern, 2003). Immunohistochemically, FGF-1 protein was localised in the cytoplasm of spermatogonia, and spermatids, Sertoli and Leydig cells in both the normal bucks and the scrotal testes of the cryptorchid bucks. Similar data have also been reported in other mammals (Wahlgren, 2003; Schön \& Blottner, 2004). Uniformity in FBFs expression in both studied groups is suggestive of similarity in structure and function of testes parenchyma and stroma. This is a further proof of absence of bilateral testicular pathology in unilateral cryptorchidism as Mahmoud et al. (2015) demonstrated that absence of estrogen receptor expression is an evidence of impaired fertility.

In conclusion, the histological and immunohistochemical examination failed to find signs of defective development or morphologic abnormalities in the germ cells of the scrotal testis of unilateral cryptorchid West African Dwarf bucks. Normal germ line were observed in the seminiferous epithelium and immunochemical study demonstrated matured Sertoli cells. We therefore recommend that castration of scrotal testes in naturally unilateral caprine cryptorchidism may not be a necessity as the contralateral scrotal testes is structurally and functionally normal.

\section{REFERENCES}

Akre, O., A. Pettersson \& L. Richiardi, 2009. Risk of contralateral testicular cancer among men with unilaterally undescended testis: A meta analysis. International Journal of Cancer, 124, 687-689.

Barqawi, A, H. Trummer, \& R. Meacham, 2004. Effect of prolonged cryptorchidism on germ cell apoptosis and testicular 
sperm count. Asian Journal of Andrology, 6, 47-51.

Bearden, H. J., J. W. Fuquay \& S. T. Willard, 2004. Spermatogenesis and Maturation of Spermatozoa. Applied Animal Reproduction. Upper Saddle River, NJ: Pearson Prentice Hall, pp. 75.

Beardsley, A., D. Robertson \& L. A. O'Donnell, 2006. Complex containing alpha6beta1-integrin and phosphorylated focal adhesion kinase between Sertoli cells and elongated spermatids during spermatid release from the seminiferous epithelium. Endocrinology, 190, 759-770.

Bilinska, B., M. Kotula-Balak, M. Gancarczyk \& J. Sadowska, 2003. Tabarowski, Z. \& A. Wojtusiak, Androgen aromatization in cryptorchid mous etestes. Acta Histochemica, 105, 57-65.

Chen, G., L. Yuan, C. Li \& Z. Yan, 2015. The histologic characteristics of yak cryptorchidism. Acta Veterinaria et Zootechnica Sinica, 46, 2282-2290.

Chiarini-Garcia, H., D. Alves-Freitas, I. S. Barbosa \& F. R. Almeida, 2009. Evaluation of the seminiferous epithelial cycle, spermatogonial kinetics and niche in donkeys (Equus asinus). Animal Reproduction Science, 116, 139-154.

Chung, E. 2011. Cryptorchidism and its impact on male fertility: A state of art review of current literature. Canadian Urological Association Journal, 5, 210-214.

Cobellis, G., C. Noviello, F. Nino, M. Romano, F. Mariscoli, A. Martino, P. Parmeggiani \& A. Papparella, 2014. Spermatogenesis and cryptorchidism. Frontiers in Endocrinology (Lausanne), 5, 63.

Goel, P., J. D. Rawat, A. Wakhlu \& S. Kureel, 2015. Undescended testicle: An update on fertility in cryptorchid men. Indian Journal of Medical Research, 141, 163-171.

Guraya, S.S., 2000. Cellular and molecular biology of capacitation and acrosome reaction in spermatozoa. International Review of Cytology, 199, 1-64.
Hadziselimovic, F. 2008. Successful treatment of unilateral cryptorchid boys risking infertility with LH-RH analogue. International Brazilian Journal of Urology, 34, 319-328.

Hadziselimovic, F. \& D. Zivkovic, 2007. Is the prohibition of hormonal treatment for cryptorchidism, as suggested by the Nordic consensus group, justifiable? Acta Paediatrica, 96, 1368-1369.

Hsu, S. M. \& L. Raine, 1981. Protein A, avidin, and biotin in immunohistochemistry. Journal of Histochemistry and Cytochemistry, 11, 1349-1353.

Huff, D. A., D. M. Fenig, D. A. Canning, M. G. Carr, S. A. Zderic \& H. M. Snyder, 2001. Abnormal germ cell development in cryptorchidism. Hormone Research, 55, 11-17.

Hutson, J. M., 2013. Undescended testis: The underlying mechanism and the effects on germ cells that cause infertility and cancer. Journal of Pediatric Surgery, 48, 903-810.

Junior, A. A., L. S. Oliveria, A. C. Assis Neto, F. R. Alves, M. A. Miglino, M. A. Carvalho, 2012. Spermatogensis in goats with or without scrotum bipartition. Animal Reproduction Science, 130, 42-50.

Kojima, Y., 1994. Ultrastructure of goat testes: Centriolar adjunct in spermiogenesis. Journal of Veterinary Medical Science, 56, 259-267.

Liu, F., H. Huang, Z. L. Xu, X. J. Qian \& W. Y. Qiu, 2012. Germ cell removal after induction of cryptorchidism in adult rats. Tissue Cell, 44, 281-287.

Lydka, M., M. Kotula-Balak, I. Kopera-Sobota, M. Tischner \& B. Bilińska, 2011. Vimentin expression in testes of Arabian stallions. Equine Veterinary Journal, 43, 184-189.

Maekawa, M., K. Kamimura \& T. Nagano, 1996. Peritubular myoid cells in the testis: Their structure and function. Archives of Histology and Cytology, 59, 1-13.

Mahmoud, I. J., M. O. Selman \& W. R. A. Shebeb, 2015. Chronology of estrogen receptor expression in testes of mouse em- 
bryos. Turkish Journal of Medical Sciences, 45, 526-533.

Makinen, S., S. Makela, Z. Weihua, M. Warner, B. Rosenlund \& S. Salmi, 2001. Localization of oestrogen receptors alpha and beta in humantestis. Molecular Human Reproduction, 7, 497-503.

Mohammed, A. H. S., D. H. Kadium \& A. K. Ebed, 2011. Some morphometric and histological description of the seminiferous tubules in the testis of indigenous male goats (two years old). Kufa Journal of Veterinary Medical Science, 2, 19-29.

Nanjappa, M. K., R. A. Hess, T. I. Medrano, S. H. Locker, E. R. Levin \& P. S. Cooke, 2016. Membrane-localized estrogen receptor 1 is required for normal male reproductive development and function in mice. Endocrinology, 157, 2909-2919.

O’Donnell, L., P. K. Nicholls, M. K. O’Bryan, R. I. McLachlan \& P. G. Stanton, 2011. Spermiation: The process of sperm release. Spermatogenesis, 1, 14-35.

Okpe, G. C. \& D. N. Ezeasor, 2016. Influence of naturally unilateral cryptorchidism on the histomorphometry of the testes and daily sperm production in West African Dwarf goats. Iranian Journal of Veterinary Research, 17, 13-19.

Onyango, D. W., E. O. Wango, G. E. Otiang'aOwiti, D. Oduor-Okelo \& G. Werner, 2000. Morphological characterization of the seminiferous cycle in the goat (Capra hircus): A histological and ultrastructural study. Annals of Anatomy, 182, 235-241.

Ortavant, R., 1958. Study of spermatogonial generations in the ram. Comptes rendus des séances de la Société de biologie et de ses filiales, 148, 1958-1961.

Sarma, K. \& J. Devi, 2012. Changes in the seminiferous epithelium of the testes during postnatal development in Assam goat. Anatomy Research International, $\mathrm{http}: / / \mathrm{dx}$. doi. org/10.1155/2012/620924.

Schön, J. \& S. Blotter, 2004. Testicular FGF-1 protein is involved in Sertoli cell spermatid interaction in roe deer. General and Comparative Endocrinology, 139, 65-73.
Sengupta, P., 2012. Challenge of infertility: How protective the yoga therapy is? Ancient Science of Life, 32, 61-62.

Singh, A. \& D. Ezeasor, 1989. Ultrastructure of Sertoli cells in scrotal testis of unilateral cryptorchid goat. Progress in Clinical and Biological Research, 296, 159-164.

Tekgul, S., H. Riedmiller, E. Gerharz, P. Hoebeke, R. Kocvara \& R. Nijman, 2009. The cryptorchidism: Guidelines on pediatric urology. Arnhem: European Urology, European Society for Paediatric Urology, 8-11.

Trussell, J. C. \& P.A. Lee 2004. The relationship of cryptorchidism to fertility. Current Urology Reports, 5, 142-148.

Veronesi, M. C., E. Riccardi, A. Rota, \& V. Grieco, 2009. Characteristics of cryptic/ectopic and contralateral scrotal testes in dogs between 1 and 2 years of age. Theriogenology, 72, 969-977.

Wagener, A., S. Blottner, G. Göritz, W. J. Streich \& J. Fickel, 2003. Differential changes in expression of $a$ and $b$ FGF, IGF-1 and -2 , and TGF- $\alpha$ during seasonal growth and involution of roe deer testis, Growth Factors, 21, 95-102.

Wahlgren, A. 2003. Growth factors in spermatogenesis. PhD thesis, Department of Women and Child health, Karolinska Institute, Stockholm, Sweden.

Wrobel, K. H., 1998. Male reproductive system. In: Textbook of Veterinary Histology, $5^{\text {th }}$ edn, eds H. D. Dellmann \& J. A. Eurell, Williams and Wilkins, Pennsylvania, USA. pp. 226-235.

Paper received 15.07.2016; accepted for publication 30.09.2016

\section{Correspondence:}

G. C. Okpe

Department of Veterinary Anatomy, University of Nigeria, Nsukka, Nigeria, e-mail: godwin.okpe @unn.edu.ng 